Dosier: Vida en la calle

\title{
Etnografía callejera \\ Una propuesta desde las calles de Bogotá, Colombia
}

\author{
Stray ethnography \\ A situated proposal on the streets of Bogotá, Colombia
}

Etnografia da rua

Uma proposta desde as ruas de Bogotá, Colômbia

Nataly Camacho Mariño ${ }^{1}$

Carolina Rodríguez Lizarralde ${ }^{2}$

\begin{abstract}
Resumen: A partir de las experiencias personales que vivimos como investigadoras en las calles de Bogotá, Colombia, en el presente artículo reflexionamos sobre las implicaciones de construir una etnografía callejera como la forma de estudiar y entender la calle desde las experiencias de quienes la viven. De igual manera, proponemos situar la calle como un concepto analítico dentro de las ciencias sociales, que se caracteriza por ser pluriespacial, multitemporal y polifónico, atravesado por las relaciones de poder entre los distintos actores que la construyen y le dan significado.
\end{abstract}

Palabras clave: Calle; Experiencias; Etnografía; Instituciones; Relaciones de poder.

Abstract: From our personal experiences, which we lived as researchers on the streets in Bogotá, Colombia, this paper studies the consequences of constructing a stray ethnography as a result of understanding the "street" based on people who have lived it. Moreover, we propose that the street is an analytic concept in the social sciences, characterized for being multi-located, multi-temporal and polyphonic. The street is composed of power relations between different subjects who set it up and give its meaning.

Keywords: Street; Experiences; Ethnography; Institutions; Power relations.

Resumo: Partindo das nossas experiências pessoais como pesquisadoras e autoras nas ruas de Bogotá, Colômbia, no presente artigo nós refletimos sobre as implicações de construir uma etnografia da rua como forma de estudar e entender a rua a partir das pessoas que vivem nela. Do mesmo jeito, nós propomos posicionar a rua como um conceito analítico das ciências sociais, caracterizado por ser pluriespacial, multitemporal e polifônico trespassado pelas relações de poder entre os distintos atores que a constituem e lhe dão significado.

Palavras-chave: Rua; Experiências; Etnografia; Instituições; Relações de poder.

\footnotetext{
${ }^{1}$ Université Paris Diderot 7 (Paris, França).

${ }^{2}$ Universidad Nacional de Colombia (UNC, Bogotá, Colômbia).

autoras.datos_biográficos
}

Civitas, Porto Alegre, v. 19, n. 1, p. 11-27, enero-abr. 2019

Este artigo está licenciado sob forma de uma licença Creative Commons Atribuição 4.0 Internacional, que permite uso irrestrito, distribuição e reprodução em qualquer meio, desde que a publicação original seja corretamente citada. https://creativecommons.org/licenses/by/4.0/deed.pt BR 


\section{Introducción}

Este artículo nace de una reflexión conjunta acerca de las cuestiones metodológicas de aquello que significa hacer una investigación en ciencias sociales sobre la vida en la calle. Partiendo desde nuestras propias prácticas investigativas - una de nosotras desde la mirada de la ciencia política y la otra desde una mirada antropológica - y compartiendo una parte de nuestros "terrenos" respectivos en la ciudad Bogotá, la intención con el presente texto es explorar y analizar los diversos caminos posibles de un trabajo empírico con jóvenes en situación de calle, usuarios y usuarias de drogas.

En el caso colombiano, las personas que viven en la calle son denominadas administrativamente como ciudadanos y ciudadanas habitantes de calle. Esta categoría engloba múltiples formas de vivir en la calle. Es decir, ella hace referencia a una heterogeneidad de experiencias en donde el espacio público es concebido como un lugar de habitación. Según el último censo de habitantes de calle, realizado en Bogotá en el 2017, 9.538 personas se encuentran actualmente en esta situación. 1.061 son mujeres y 8.477 son hombres, equivalentes al $11,10 \%$ y $88,90 \%$ respectivamente. Es en el centro de la ciudad donde esta población está mayormente concentrada (Dane, 2017).

Es importante aclarar que eso que nosotras llamamos aquí la vida en la calle hace referencia a solo una de las formas de vida posible en calle. Se tratará aquí de la experiencia cotidiana entre el uso dependiente de drogas duras, ${ }^{1}$ la precariedad extrema y la confrontación permanente a situaciones de violencia por parte de jóvenes o adultos jóvenes, hombres y mujeres, entre los 14 y los 30 años, quienes se asentaban principalmente en el centro de la ciudad.

En términos epistemológicos, una interrogación que nos resulta central, en el deseo de comprender la experiencia de la calle, es saber qué entender por "calle" desde el punto de vista de las personas que la viven ¿Se trata solamente del espacio público como se entiende en el sentido común y como se asume en los contextos institucionales que prestan atención a las personas en esta situación? ¿Qué características tiene la "calle" de las personas que encontramos? Basándonos en nuestros trabajos de campo, vamos a entender aquí la calle como una experiencia de vida que se territorializa no solamente en el espacio público, sino en una red de espacios diversos (públicos, privados, familiares, institucionales) que es construida por cada una de las personas a partir de su propia trayectoria vital, con el fin de garantizar la supervivencia cotidiana en situaciones de precariedad y consumo dependiente de drogas.

\footnotetext{
${ }^{1}$ En Colombia, la droga más consumida en el contexto urbano que nos concierne es el bazuco o basuco, residuo de la pasta-base de cocaína.
} 
En términos metodológicos, partimos de la importancia de acercarse a una comprensión de la vida en la calle, a partir de un trabajo de campo de inmersión prolongada en el mundo callejero, donde el investigador no recurre simplemente a informarse, estableciendo una distancia con sus interlocutores, sino donde vínculos más horizontales puedan ser creados. Solamente "una observación rigurosa, por una impregnación lenta y continua" - retomando las palabras de François Laplantine (1998, p. 11) sobre el método etnográfico - y entablando una relación personal con aquellas personas que viven en la calle y frecuentan espacios de consumo de drogas, puede permitirnos la comprensión de su propia realidad social, en el contexto social y espacial en el que ella toma lugar.

Empero, como ocurre con diversos escenarios urbanos marginalizados y confrontados cotidianamente a la venta y el uso de drogas, una mirada social dominante parece definirlos como contextos peligrosos, con los cuales, si es posible, es mejor no entrar en contacto (Bourgois, 2003; Epele, 2010; Frúgoli y Cavalcanti, 2013; Rui, 2012). Es probablemente en esta mirada social dominante sobre la calle que se encuentra una respuesta al hecho que la gran mayoría de trabajos empíricos en ciencias sociales sobre la vida en la calle en Bogotá (y en otras ciudades alrededor del mundo), se realicen en espacios institucionales o en otros espacios urbanos públicos o privados que se alejan de los espacios callejeros.

Y sí la calle es percibida como un contexto "peligroso", sí muchos de los espacios que la conforman son percibidos socialmente como lugares inseguros $\mathrm{y}$, la verdad sea dicha, es innegable que diversos tipos de violencia convergen en el contexto callejero (rechazo cotidiano evidenciado en agresiones verbales o físicas contra las personas en situación de calle, abuso de autoridad de parte de la policía, formas de control internas a lugares de venta y consumo de drogas, acciones de delincuencia, agresiones sexuales o situaciones de venganza entre las personas que viven la calle) ¿cuál es entonces la viabilidad de una inmersión etnográfica? A partir de nuestras propias trayectorias y experiencias de campo, que comenzaron en contextos institucionales para dirigirse progresivamente a contextos callejeros, y de los cuestionamientos tanto epistemológicos como metodológicos ya presentados, nos proponemos en este artículo poner en diálogo una problematización sobre la noción de "calle" y un enfoque de trabajo de campo etnográfico en contextos callejeros. El análisis de este diálogo nos permite reflexionar sobre la importancia de pensar a las personas en situación de calle como sujetos activos de su propia realidad y no como sujetos pasivos, tal como son considerados de manera recurrente en contextos institucionales. 


\section{Posibilidades para repensar las investigaciones sobre la "calle" dentro de las instituciones}

Aunque nuestros trabajos iniciaron por separado, ambos se ubicaron en sus comienzos dentro de los centros de acogida para habitantes de calle. Fue precisamente en una de estas instituciones donde nos conocimos y donde una reflexión conjunta sobre cómo investigar la vida en la calle emergió. Cada una de nosotras realizó dos años de campo tanto en contextos institucionales como callejeros. ${ }^{2}$ Para abordar la vida en calle desde espacios institucionales, nos fue necesario como investigadoras comprender que estábamos, a los ojos de las personas encontradas, legitimadas desde una figura normativa que preorientaba nuestro quehacer, que principalmente consistía en la denominación "profe", término utilizado de manera general para llamar a los funcionarios de los centros de acogida. Está claro, como ya se ha dicho varias veces en etnografía, que la interacción entre el investigador y los actores es siempre contextualizada (Girola, 1996, p. 87). No obstante, la categorización de "profes" que nos fue atribuida no nos impidió buscar espacios o estrategias de trabajo que nos liberaran de los encuentros condicionados por la institución, creando otras formas de interacción con las y los jóvenes. A nuestro parecer, la identificación con unas "profes" que no ejercían control sobre sus cuerpos ni sus dinámicas dentro de los servicios de atención, así como nuestras edades (25 años) que nos hacían jóvenes también, nos permitió ganar confianza rápidamente. En la institución nuestra identidad de género también desempeñó un rol importante para acercarnos a relatos íntimos con otras jóvenes mujeres y ser vistas como sus confidentes; y con los hombres jóvenes se daban relaciones de recordación a hermanas, ex parejas o profesoras que habían conocido en otros escenarios, situación que les permitía sentarse horas a conversar con nosotras en algún rincón, siempre que las dinámicas del centro lo permitieran.

Es importante aclarar que nosotras no vivíamos en el centro de la ciudad, pero sí en barrios conocidos por ellas y ellos, lo que nos permitía estar ligadas a contextos populares similares a donde crecieron, o donde vivían sus familiares o amigos, así como afirmar que contábamos con saberes más cercanos a sus

\footnotetext{
${ }^{2}$ Para el caso de Carolina Rodríguez, el acercamiento a la calle inició en junio 2011. Sin embargo, el trabajo de campo propiamente investigativo y sistemático en el marco de la etnografía se hizo entre enero 2013 y mayo 2014. En cuanto a Nataly Camacho, para la preparación de su tesis doctoral el trabajo etnográfico se realizó en tres estadías de campo entre febrero 2014 y junio 2016 (febrero-mayo 2014, diciembre 2014-febrero 2015, octubre 2015-junio 2016) y visitas precisas para completar la colecta de datos etnográficos entre agosto 2016 y enero 2017. Nuestros respectivos trabajos de campo confluyeron entre los meses de febrero y mayo 2014, cuando nos encontramos en Luna-Park, un centro de acogida diurno para mujeres jóvenes "habitantes de la calle" de la alcaldía de Bogotá.
} 
experiencias. Así mismo, haber crecido en Kennedy (al sur de Bogotá) le dio a una de nosotras la posibilidad de conectar con historias de la ciudad, prácticas barriales y personajes reconocidos, mientras venir de provincia significó para la otra relacionarse con historias de migración y desplazamiento propias, o de sus familias. ${ }^{3}$

En esta interacción entre quienes viven la calle y nosotras (investigadoras), mediadas por la institución, reflexionamos sobre nuestro rol y formas de hacer investigación, así como nos planteamos deconstruir los discursos y transformar las prácticas institucionalizadas, a través de acciones que mostraban diferencias con quienes brindaban atención directa en los centros de acogida, por ejemplo, comiendo en sus mismos platos, durmiendo en sus dormitorios y compartiendo comida diferente a la que se ofrecía en la institución. Igualmente, nos dimos cuenta de la importancia de salir de las instituciones para caminar la calle en compañía de quienes la viven, haciendo recorridos de varias horas, durante el día y la noche, para así acercarnos a sus vidas cotidianas.

Salir de la institución para ir con las y los jóvenes a caminar la calle, a pie y sin los mecanismos institucionales, no fue una acción bien vista dentro de los muros institucionales, pues eran situaciones que se salían de las dinámicas características, lo que nos llevó a repensar la institución, por medio de cuestionar sus procesos de reproducción discursiva, para gestar y sostener aquellos que significaban nuevas formas de relacionarnos. El reparo más frecuente implicaba cuestionar la confianza que depositamos en jóvenes callejeros, que podían traicionarnos al interior de las ollas y hacernos "cosas malas" como mujeres, y el más problemático era eximir a la institución de cualquier responsabilidad por nuestras acciones como investigadoras.

Por tanto, desde la institución y en la institución, la calle se vive diferente, o no se vive; y al interior de los centros de acogida también se evita contagiar a la institución de las dinámicas callejeras, desplegando dispositivos de control y disciplinamiento (Goffman, 1961; Foucault, 1975; Tejeda, 2010; Rodríguez, 2014) que buscan eliminar comportamientos "propios" de calle, tales como el consumo de drogas, los robos, el vocabulario, el uso adecuado de los baños y los modales al momento de comer.

En el día a día de las instituciones se ponen en juego los significados de la calle, y debido a que las instituciones están compuestas por personas,

\footnotetext{
${ }^{3}$ Con quienes compartimos tienen vínculos con sus familias, que, si bien viven en condiciones precarias, dadas por las desigualdades sociales en Colombia, no se encuentran desprovistas de todo. La principal razón por la que estos jóvenes se encuentren en la calle es el uso de drogas.
} 
se terminan reproduciendo discursos y prácticas que a veces están lejos de entender la calle en su complejidad, pues se limita a ver la calle desde la orilla institucional, y solo la experiencia que se vive en interlocución directa entre quienes la viven y quienes hacen parte del aparato estatal. Las prácticas desplegadas por las instituciones van desde el asistencialismo o la ayuda humanitaria, hasta fases de "reintegración" y el abandono definitivo de la calle. Dichas prácticas se materializan por medio de discursos sobre la seguridad, la pobreza, la religión, las divisiones de género, el "deber ser" social, la familia y los medios para alejarse de la calle. Por ello, asumimos que las políticas sociales producen cuerpos objeto/sujeto de la intervención (Rodríguez, 2014), bien sea en manos del estado $u$ otras organizaciones que buscan controlar, reducir y luchar contra este fenómeno.

En esta medida, la diferencia entre permanencia y tránsito en la calle se convierte en el argumento para promover una salida de la "calle", y fundamenta el discurso de "evitar" llegar/caer en ella. Por ello es más fácil diseñar propuestas que concentren a la población en el lugar "seguro" de la institución y estudiar allí los temas de investigación con las personas, a permitirse buscarlas en los espacios físicos que permanecen. Este discurso del miedo atraviesa las metodologías, llevando a que en la institución se apliquen instrumentos formales de investigación, obligando a la realización de entrevistas, grupos focales y/o talleres, que además están permeados por la mirada institucional y exigen unos requerimientos para su realización, tales como establecer horarios de acuerdo a franjas de atención, aportar a los objetivos de los programas y proyectos, y dar recomendaciones para el quehacer institucional, que pocas veces se contemplan y asumen responsablemente por parte de quienes dirigen o coordinan los procesos.

Reconocemos la importancia de los espacios institucionales como parte de las voces que construyen la "calle", mediante la producción de discursos y prácticas que atraviesan las vidas de quienes viven la calle, así como las posibilidades de agencia, resistencia y confrontación que generan los programas de atención y/o asistencia a habitantes de calle ofertados desde las instituciones distritales en Bogotá u otros proyectos dirigidos desde organizaciones no gubernamentales. Sin duda, estudiar los espacios institucionales nos permite entender y situar la calle como experiencia, siendo conscientes que una y otra se necesitan para mantener relaciones de poder que pasan por la cohesión, la eliminación y la legitimidad de las decisiones de gobernabilidad (Foucault, 2004).

Trabajar en la institución durante la investigación, y ser parte, a los ojos de las personas encontradas, de una voz institucional o institucionalizada, 
nos llevó a que las relaciones de poder - terreno de la ciencia política que construimos como investigadoras, estuvieran sustentadas parcialmente en el vínculo institucional - como en el caso de la identificación como "profes". Dentro de los contextos institucionales pudimos conversar con varios jóvenes que nos crearon la necesidad de comprender con mayor profundidad aquello que llamaban "calle" y de experimentar cómo se da el trabajo de campo en esa calle. Fue precisamente a través de esas conversaciones y de esas menciones a la "calle" que comprendimos que ésta se nos escapaba quedándonos en los muros de la institución. Así, los relatos que nos habían sido contados dentro de la institución evidenciaban una confianza con las y los jóvenes a través de la escucha, pero solo nos permitían llegar a una calle relatada/contada y no a la calle vivida. Para acceder a una comprensión de la vida en la calle necesitábamos ir a la calle, acercarnos a espacios callejeros y experiencias callejeras directamente allí donde ellas cobran vida, y no solamente limitarnos al relato que sobre ellas nos llegaba. La articulación de los relatos que nos eran contados en la institución y la inmersión en contextos callejeros sólo podía permitirnos una comprensión más completa y compleja de lo que es la "calle" para las y los jóvenes que conocimos.

No obstante, salir a la calle implicó, por un lado, enfrentarnos a los miedos de ser mujeres y estar expuestas a agresiones (principalmente sexuales) en contextos callejeros; por el otro, poner en juego nuestras feminidades y no reconocernos como usuarias de drogas dentro de las ollas. Dicha situación generó a la vez la desconfianza por parte de las estructuras ilegales o personajes como los "jíbaros" [vendedores de drogas], frente a rumores de "ser policías" infiltradas. Desconfianza que se mitigaba relativamente por el hecho de estar siempre acompañadas de personas habituadas a frecuentar las ollas y reconocidas en estos lugares. Finalmente, otra forma de estar en la calle con las y los jóvenes nos implicó destinar recursos económicos propios para invitarles algo de comer, beber o fumar, así como monedas para máquinas de azar u otras necesidades. Lo anterior, nos dejó ver que las limitaciones al interior de la institucionalidad también eran confrontadas con unas dificultades propias de estar (y no solo transitar) en la calle y vivir las experiencias desde nuestros cuerpos, leídos como femeninos.

\section{La calle como experiencia y lugar de etnografía}

Nuestra salida del contexto institucional hacia la calle, para realizar trabajo de campo, se dio gracias a los mismos jóvenes que frecuentamos en las instituciones. Los centros de acogida donde trabajamos juntas eran 
hogares-día que funcionaban desde las siete de la mañana hasta las dos o tres de la tarde. Después de almuerzo, las y los jóvenes dejaban la institución para dirigirse generalmente al centro de la ciudad, donde su experiencia callejera continuaba. Así, a la hora de la salida, salíamos con ellas y ellos para caminar, acompañarlos en los trabajos ${ }^{4}$ que realizaban - como vender dulces, cantar en los buses o reciclar - e ir de fiesta a los lugares de venta y uso de drogas conocidos como ollas. En las ollas, establecimientos festivos como tabernas, bares o discotecas permitían una fiesta continua y sin límites, en algunas ocasiones hasta veinticuatro horas al día, siete días a la semana. A pesar de las situaciones de violencia que se viven al interior a causa, principalmente, del control armado por parte de redes de tráfico de drogas, las ollas son lugares de sociabilidad para las personas que las frecuentan, y eran lugares donde generalmente terminaban nuestras largas caminatas juntos.

La primera vez que salimos juntas de la institución fue con Edwin y Jonathan, ${ }^{5}$ dos jóvenes transgénero a quienes acompañamos a trabajar en los buses antes de dirigirnos a una olla para compartir una cerveza en una de las tabernas del lugar. Fueron ellos quienes nos propusieron ir a la olla y estaban muy sorprendidos de que nosotras aceptáramos sin problema. Las ollas del centro de la ciudad son consideradas desde la mirada institucional, y más generalmente desde la mirada social, como lugares sumamente peligrosos. En aquella ocasión nos dirigíamos a la que era considerada la olla más peligrosa de la ciudad: La Ele. La sorpresa de Edwin y Jonathan se sustentaba en el hecho que nosotras no manifestáramos miedo de entrar y quedarnos un poco en aquellas cuadras controladas por grupos armados. La verdad es que nosotras ya conocíamos la olla. Cada una, en sus trabajos de campo correspondientes, ya había tenido la oportunidad de ir. El hecho de conocer un poco la olla y de aceptar ir con ellos permitió que nuestro estatus de "profes" fuera revalorado a sus ojos. Edwin y Jonathan se permitieron desde ese momento hacernos comentarios sobre nuestra apariencia física. La manera - descomplicada para ellos - de cómo nos vestíamos los intrigaba, así como la falta de maquillaje en nuestros rostros; no tuvieron entonces ningún reparo en hacernos preguntas más personales: ¿por qué se visten así? ¿son lesbianas?... Preguntas que dentro de la institución nunca nos habían hecho. Como lo dice Michel Naepels (2011, p. 31), "en la relación etnográfica, es el investigador como sujeto quien es

\footnotetext{
${ }^{4}$ Todos nuestros interlocutores denominaron con el término "trabajo" a las actividades que realizan para conseguir dinero. No siendo del interés de este artículo trabajar dicha cuestión, dirigimos al lector hacia otros trabajos que la profundizan. Ver, entre otros, Gaboriau, 1993; Girola, 2007.

${ }^{5}$ Los nombres de las personas han sido modificados.
} 
movilizado", y allí, caminando hacia La Ele y conociéndonos mutuamente con preguntas diversas, éramos nosotras como sujetos quienes nos movilizábamos y era precisamente como sujetos que estábamos siendo reconocidas por Edwin y Jonathan.

Dentro de la olla nos encontramos con otras y otros jóvenes que nos habíamos cruzado en las instituciones, o con quienes habíamos ya conversado. Nos saludaban sorprendidos de vernos allí, al mismo tiempo que una suerte de complicidad emergía. Fue el caso, por ejemplo, con Johana y Jenny, dos hermanas que iban de vez en cuando a los centros de acogida que nosotras visitábamos y que el día de nuestra visita a la olla con Edwin y Jonathan estaban ahí. Después del encuentro en la olla, la relación con ellas dentro de los espacios institucionales se afianzó. No sólo nosotras estábamos interesadas en ellas, en sus vidas, en sus experiencias en la calle, sino que ellas también se interesaron en nosotras con el fin de saber dónde vivíamos, dónde habíamos crecido, cuáles eran nuestras historias de amor. Dichas inquietudes se convirtieron en temas de conversación a partir de las cuales íbamos encontrando puntos en común entre nosotras.

Así, salir de la institución con las y los jóvenes nos permitió afianzar nuestros lazos de confianza y entablar relaciones más horizontales. No solo escuchábamos sus relatos en las instituciones, sino que íbamos - sin intenciones normativas - allí donde ellos permanecían, y eso ante sus ojos nos acercaba, pues además de nuestra juventud, ahora se compartían también algunas experiencias callejeras como caminar, reciclar o ir de fiesta a las ollas, de la misma manera que algunas experiencias en relación a nuestras propias trayectorias de vida. Esa cercanía generaba que las conversaciones fueran más fluidas y sinceras, así estas tuvieran lugar en contextos institucionales y fueran grabadas, pues, claro está, todas las personas que encontrábamos estaban al tanto que nosotras realizábamos un trabajo universitario.

Es precisamente después del encuentro en la olla que, Jenny nos cuenta su experiencia en la calle. Su relato es uno de los primeros en hacernos tomar conciencia que la calle, a los ojos de las personas que la viven, es mucho más que el espacio público. Cuando estas personas se refieren a la "calle", incluyen una diversidad de prácticas, aprendizajes, personas y espacios en el sentido que le dan a esta palabra. Jenny, por ejemplo, cada vez que hacía referencia a su experiencia cotidiana "en la calle", nos hablaba de un conjunto de lugares en donde se incluían espacios públicos, ollas algunas residencias en los alrededores de las ollas donde ella podía pagar un cuarto, o algunas casas donde ella conocía personas que le permitirían dormir, bañarse y consumir drogas. 
Jenny: [E]ntonces yo me volví volar de la fundación, me fui pa' donde el cucho, me fui pal' Samber, me conocí un man en el Samber, me conocí un man en la [avenida] Décima. Me la pasaba por ahí y hacía ratos, hasta que me fui otra vez para Soacha. No llegué a mi casa, sino consuma y consuma. Me la pasaba de olla en olla, de casa de jíbaro en jíbaro hasta que... Uy yo diré un año, como un año total en la calle, calle, calle sin llamar a mi mamá ni nada.

Investigadora: Pero, ¿qué es para ti estar en la calle, calle, calle?

Jenny: Pues no bañarse, consumir todos los días, casi ni comer, no dormir, pasársela en la calle porque yo no duermo casi, cuando estoy consumiendo yo no duermo. Yo duermo, digamos, cuando llego a "patio" o cuando estoy en la casa, de resto no; o cuando ya estoy muy mamada [cansada] de fumar, que tiene que pasar por ahí una semana, unos ocho días, de resto no. Eso. Entonces ya, otra vez, me fui para donde el cucho.

En este fragmento, Jenny pone en evidencia tres dimensiones que atraviesan lo que significa para ella estar en la "calle, calle": una dimensión espacial, otra temporal y en últimas, la dimensión relacional. El eje de articulación de estas tres dimensiones es el consumo de drogas, y particularmente el consumo de bazuco.

En la dimensión espacial de la calle, Jenny menciona varios espacios que no son necesariamente "espacios públicos", pero que para ella hacen parte de su experiencia cotidiana en la calle. Ella hace referencia inicialmente a una fundación, que se trata más precisamente de una fundación cristiana para la "rehabilitación" del consumo de drogas, donde su madre la había internado algunos meses antes. Anterior a su internación en dicha institución cristiana, ella ya había pasado varios años en calle, había ingresado a la fundación y se había fugado. Es por esa razón que ella expresa "me volví a volar". No creemos que esta fundación sea parte de lo que Jenny concibe como "calle, calle", pero situar este tipo de espacios institucionales en la trayectoria de vida de las personas en situación de calle y consumo de drogas, no deja de ser pertinente para comprender el trasfondo de una relación de varios años con el universo callejero. De hecho, casi todas personas que conocimos durante nuestros trabajos de campo habían pasado por este tipo de internados e incluían esa experiencia cuando hablaban de su experiencia en calle.

Jenny menciona también al Samber, apelativo con el cual es reconocida una de las ollas más importantes de Bogotá, situada en un barrio popular (San Bernardo) del centro de la ciudad. Sin embargo, ella no habla solo de esta olla sino de varias ollas donde ella puede ir para consumir. ¿Pero qué es exactamente una olla? Como ya lo mencionamos, se trata de espacios urbanos 
dedicados a la venta y al consumo de drogas, pero más allá de esta definición tan general, existen dos tipos de ollas principalmente: por un lado, ollas, con nombre definido como el Samber, que ocupan varias calles (espacio público e inmuebles) de un barrio residencial o comercial, que son controladas por redes de tráfico de drogas y grupos armados que garantizan la "seguridad" del lugar. Por otro lado, están las ollas que se ubican en casas de cualquier barrio de la ciudad, a diferencia de las primeras, su existencia suele ser clandestina ante la administración distrital y la policía.

Respecto a la dimensión espacial, Jenny menciona igualmente espacios institucionales que ella llama "patios". Esta apelación es la manera como las personas en situación de calle y consumo de drogas en contextos precarios hacen referencia a los centros de acogida de instituciones gubernamentales $o$ no-gubernamentales, en los cuales ellos y ellas pueden dirigirse durante el día para acceder a diversos servicios: baños, duchas, alimentación, enfermería, algunos espacios para dormir, talleres de manualidades, etc., como es el caso de las instituciones donde nosotras realizamos el trabajo de campo. La importancia de estos "patios" en la vida cotidiana de las personas que viven la calle, no puede ser subestimada. Pero más allá de las razones institucionales ligadas a la asistencia, es importante pensar los "patios" como lugares que permiten la subsistencia en calle bajo un consumo dependiente de drogas duras. En Francia, por ejemplo, algunos autores han mostrado los diferentes tipos de relaciones que pueden crearse con las instituciones de asistencia por parte de las personas en situación de calle (Girola, 2007; Pichon, 2010). La intencionalidad normativa de las instituciones puede ser eximida de la relación que se crea con ellas y el lugar de estas estructuras en la cotidianidad de estas personas puede darse en términos utilitarios (Girola, 2007, p. 248). En el caso bogotano, los "patios" entran sin lugar a dudas en la red de espacios que permiten la subsistencia física o material. Jenny lo dice claramente: solo estando en los "patios" o la casa de su madre, ella puede dormir y descansar después de varios días de consumo continuo de drogas.

Para terminar con la dimensión espacial y articular ésta con la dimensión relacional, veamos lo que Jenny nos dice sobre la casa del "cucho" [hombre anciano] y la casa de algunos "jíbaros" que ella conoce. Ella presenta estos lugares como haciendo parte de lo que ella llama la "calle, calle", a pesar de que no se trate de un espacio público. El "cucho", es un hombre mayor que recibe a Jenny de vez en cuando, le da droga, le da comida, la deja bañarse en su casa y descansar. Todo esto a cambio de tener relaciones sexuales con ella. El "cucho" es también consumidor de drogas y fue por ese punto en común que ellos se conocieron. Los "jíbaros" en sus casas también les dan acceso a 
drogas a cambio de relaciones sexuales. Si estos hombres que Jenny conoce se aprovechan de su vulnerabilidad y su dependencia al bazuco para intercambiar droga, comida o alguna comodidad de una noche por servicios sexuales, la relación que Jenny entabla con ellos no es completamente pasiva. Ella tuvo que "aprender" en su llegada a la calle ciertos códigos, valores y normas que están asociados a esta experiencia de vida desde los ojos de quienes la viven, como por ejemplo que en la calle "nada es gratuito".

Frente a la dimensión temporal es posible decir dos cosas: por una parte, que entre más tiempo se lleve en la calle, más espacios, más personas y más aprendizajes entran en la experiencia de la calle, y así, más posibilidades existen de mantener un ritmo continuo y prolongado de consumo de drogas en contextos precarios. Por otra parte, que la experiencia de vida en calle es un ir y venir entre diversos espacios que tienen temporalidades determinadas, por ejemplo, el acceso y permanencia en los "patios" entre las siete de la mañana y las dos o tres de la tarde que se acaba la jornada de acogida.

Así, un trabajo de campo en y sobre la calle implica replantear aquello que consideramos "campo". Si los espacios institucionales son ciertamente lugares donde el investigador puede acceder a relatos o entablar conversaciones, no podemos olvidarnos de aquellos espacios donde la experiencia callejera cobra vida. ${ }^{6}$ La red de espacios que forman la "calle" de las personas que hacen parte de nuestras investigaciones debe ser entendida como espacios posibles de investigación etnográfica. La temporalidad de la calle, de sus espacios y los ritmos de las personas que la viven también deben ser tenidos en cuenta. De la misma manera, no solamente las personas que viven la calle deben hacer parte de la comprensión de la "calle", todos aquellos que constituyen la "calle" o el entorno de la "calle" también deberían ser escuchados, en la medida de lo posible, en nuestros trabajos: los educadores de los centros de acogida, las familias de las personas en esta situación, los vecinos de las ollas.... Si bien es cierto que algunas de estas voces representan miradas dominantes o normativas, no podemos negar la presencia de estas personas, su importancia y sus interacciones en la vida cotidiana de las personas en situación de calle. La experiencia callejera de las y los jóvenes que hicieron parte de nuestras

\footnotetext{
${ }^{6}$ En el caso colombiano, y más precisamente bogotano, las investigaciones sobre la vida en la calle han sido generalmente realizadas desde espacios institucionales. Incluyendo nuestros propios trabajos, conocemos cuatro trabajos de investigación, que se han esforzado por acercarse a contextos callejeros: Amy Ritterbusch, 2011; Carolina Rodríguez, 2014; Sandra Martínez, 2015; y Nataly Camacho, 2016. A nivel internacional, trabajos como los de Philippe Bourgois (2003) en New York, Philippe Bourgois y Jeffrey Schonberg (2009) en San Francisco, Claudia Girola (2007) y Patrick Gaboriau (1993) en París se han igualmente realizado fuera de contextos institucionales.
} 
investigaciones estaba también permeada por las relaciones que tenían con los agentes institucionales, sus familias, o los vecindarios de las ollas, entre otros.

Como ya lo dijo Pierre Bourdieu, 'los lugares llamados 'difíciles' son difíciles de describir y de pensar" (Bourdieu, 1993, p. 9). La calle es una red de lugares, muchos de ellos considerados difíciles por las situaciones conflictivas que en ellos pueden desarrollarse; pero más allá de los espacios se encuentra también la connotación negativa que recae sobre la noción de calle desde una mirada socialmente compartida, cuando ésta es pensada desde su relación con el consumo de drogas, por ejemplo. "[E]s necesario substituir a las imágenes simplistas y unilaterales (aquellas vehiculadas por la prensa principalmente) - agrega Bourdieu sobre los lugares "difíciles"-, una representación compleja y múltiple, fundada sobre la expresión de esas mismas realidades en discursos diferentes, muchas veces irreconciliables" (Bourdieu, 1993). Para entender entonces la "calle" en su complejidad, necesitamos como investigadores dar cuenta de su carácter pluriespacial, multitemporal y polifónico; y en el caso de un trabajo empírico en ciencias sociales, no quedarse sólo con el relato, sino, en la medida de lo posible, ir a ver aquello que se produce socialmente en los contextos donde las prácticas y las relaciones sociales toman vida.

\section{Una etnografía de la calle desde la calle: a modo de conclusión}

Aunque nuestras problemáticas de investigación sobre la calle eran considerablemente diferentes, las dos tomamos la decisión de entender la calle desde los contextos sociales donde ella toma vida y en ese punto nuestros trabajos convergieron: Carolina Rodríguez era funcionaria dentro de la institucionalidad que formalmente atiende habitantes de calle jóvenes y se interesaba como tema de investigación en la producción de cuerpos callejeros a través de los discursos y la prácticas de la institucionalidad (Idipron) desde un enfoque de género; Nataly Camacho, quien estaba interesada en las experiencias de violencia en las ollas vividas y ejercidas por las personas en situación de calle, se dio cuenta que era necesario establecer el vínculo con la institución porque finalmente ésta hacía parte de esas "calles" y relaciones que conforman la experiencia callejera y su relación con las ollas. Sin embargo, partir de las instituciones implicaba superar la etnografía institucional y proponer la etnografía callejera con el fin de comprender las experiencias de calle, que en tan solo lo relacional conectan con una u otra institución. Al quedarnos en la institución corremos el riesgo de ver únicamente una arista de las múltiples calles que construyen quienes la viven.

Solas, en cuanto mujeres jóvenes investigadoras, nos arriesgamos cada una por nuestro lado - y algunas veces juntas - a salir de los muros de la 
institución y a acercarnos a los espacios urbanos que constituyen el universo callejero. Sin duda, estos cambios en las formas de hacer e interactuar, nos llevó a plantearnos una etnografía de la calle, que se teje con relación a las instituciones, desde y en la calle, estudiando las relaciones de poder de manera microscópica, donde se ejerce no solo poder sino resistencias (Múnera, 1996), y presentes en las cotidianidades. A partir de esta comprensión, planteamos las siguientes reflexiones:

La primera concierne el tiempo del campo. ¡Hacer etnografía toma tiempo! y perder tiempo en campo se hace necesario para darse cuenta luego que esos tiempos fueron imprescindibles para el desarrollo de la investigación (Olivier de Sardan, 1995). Además de la salida con los jóvenes de las instituciones, el trabajo etnográfico que se propuso en la calle se desarrolló igualmente a partir de repetidos recorridos en el centro de Bogotá y alrededor de las ollas. Así, nuestra presencia en los sectores del centro de la ciudad que rodean las ollas fue también legitimada desde la figura de transeúntes o de clientes de los múltiples establecimientos comerciales que, atiborrados de productos, se sitúan en esta parte del centro de la ciudad. Poco a poco, recorrido tras recorrido, nos íbamos acercando más a las personas en las ollas. Eso se logró gracias al hecho que las y los jóvenes con quienes habíamos hablado en las instituciones nos reconocían en la calle y se nos acercaban para saludarnos y conversar, aprendiendo que solo con tiempo se construyen relaciones de confianza mutua.

La confianza y la amistad que se crearon a partir de estos espacios y tiempos compartidos, es la segunda línea de reflexión que nos interesa señalar aquí. Nuestro trabajo de campo desde la calle estuvo basado en la confianza: la confianza que podíamos inspirar a estas personas de no ser, por ejemplo, periodistas o policías infiltradas - figuras que generan rechazo en el contexto callejero - y que seamos, como lo decíamos, estudiantes; además de la confianza que ellas y ellos podían generarnos, en tanto nuestros cuerpos eran leídos como femeninos en la calle, dando lugar a posibles riesgos en términos de relaciones y agresiones de tipo sexual.

Entonces, nuestras amistades (algunas persisten hoy) se basaron en el reconocimiento y la construcción de empatía. Resaltamos aquí la cercanía entre las trayectorias de vida que como jóvenes de barrios populares compartimos, porque teníamos gustos, vivencias, sujetos y territorios en común. Las personas con quienes nos cruzamos en las etnografías reconocieron nuestra subjetividad de ser mujeres jóvenes, con quienes compartían más que un espacio-tiempo de su vida en la calle, sino en las que veían un reflejo de sus historias (algunas más difíciles que otras), pero sobre todo con quienes 
se sentían escuchados, apoyados, queridos. Así, brindar un abrazo, darles nuestro número de teléfono móvil, ir a buscar a sus familiares, saludarles en la calle sin miedo y sin vergüenza, agregarles a redes sociales como Facebook, compartir un cigarro o permitirles drogarse mientras hablaban con nosotras, se convirtió en la posibilidad de acercarse a un sujeto diferente al que suelen ver en sus experiencias de calle. Se dio así una transformación en el sentido de reconocimiento de esa otredad, sin juicio, sin cuestionamiento, sin discursos obligantes del "deber ser"; sino más bien desde el aprecio y el cuidado, pues finalmente terminaron haciendo parte de nuestras vidas y nosotras parte de las de ellas y ellos.

En este marco, la palabra se liberaba, y posiblemente, en nuestros trabajos no se caía de manera directa en formalismos narrativos. Ellos y ellas nos hablaban como pares. Haber conocido con ellos y ellas la calle, sus calles, nos permitía comprender sin problema expresiones, gestos, y sí, en algún momento no entendíamos algo, recibir explicaciones siempre generosas. La etnografía, desde la inmersión profunda y prolongada, desde los vínculos personales que permite y desde la búsqueda de las relaciones más horizontales entre el investigador y los actores y actrices de su trabajo, es el método cualitativo que más favorece al entendimiento de la vida en la calle desde la calle misma. Una etnografía de la calle es escuchar las diferentes voces de los actores que la componen a modo polifonía. Es un ir y venir entre los espacios públicos y privados (instituciones, ollas, parques, cárceles, residencias familiares, inquilinatos), físicos y simbólicos que la componen. Es observar, escuchar estos espacios desde las personas que los viven, entender sus ritmos, sus temporalidades. Una etnografía de la calle es ir a la calle, es caminar, compartir, confiar... Es entender que la calle no es un espacio, es una experiencia, y que ella atraviesa nuestros cuerpos y subjetividades como investigadores que, en nuestro caso, ha llevado a narrarnos como mujeres y jóvenes.

Si bien es cierto que es difícil pensar la calle como ajena a la dinámica de las instituciones - pues incluso éstas hacen parte necesariamente de ella, se tejen como relaciones en esas múltiples "calle, calle", y hacen parte de los actores y procesos en una etnografía de la calle -, la apuesta sería entonces, si el problema investigativo se plantea desde una mirada institucional, comprender los significados que el concepto calle adquiere al hacer inmersión en las relaciones de poder existentes en dicho contexto. Entender cómo a la vez la institucionalidad estatal y no estatal desempeña un papel importante cuando se da un tratamiento politológico, pues hay relaciones de confrontación directa, asistencialismo y dominación. El análisis de las relaciones de poder en la 
calle implica observar el poder en "otras instancias" de la sociedad, cuestionar las fuentes y fundamentos del poder social, reflexionar sobre los ejercicios de ciudadanía y las prácticas sociales que se disfrazan tras la denominación "ciudadanos habitantes de calle". Así, una etnografía de la calle desde la calle tal que la concebimos aquí, implica valorar las experiencias, los cuerpos y las historias de aquellas y aquellos que viven la calle, sin negarles a estas personas un reconocimiento como agentes activos de su realidad, como sujetos políticos.

\section{Referencias}

BOURDIEU, Pierre (ed.). La misère du monde. Paris: Seuil, 1993.

BOURGOIS, Philippe. In search of respect. 2. ed. Cambridge University Press, 2003. BOURGOIS, Philippe; SCHONBERG, Jeffrey. Rithteous dopefiend. California: University of California Press, 2009.

CAMACHO MARIÑO, Nataly. Rue, drogue et violence: la survie des jeunes «habitants de rue» à Bogotá. Encyclo, n. 6, p. 17-33, 2016.

DANE. Censo de habitantes de calle 2017. Secretaría distrital de integración social, $2018<$ dane.gov.co/index.php/estadisticas-por-tema/demografia-y-poblacion/censohabitantes-de-la-calle-bogota> (23 dez. 2018).

EPELE, María. Sujetar por la herida: una etnografía sobre drogas, pobreza y salud. Buenos Aires: Paidós, 2010.

FOUCAULT, Michel. Surveiller et punir. Naissance de la prison. Paris: Gallimard, 1975.

FOUCAULT, Michel. Sécurité, territoire, population: cours au Collège de France 1977-1978. Paris: Gallimard: Seuil, 2004.

FRÚGOLI, Heitor; CAVALCANTI, Mariana. Territorialidades da(s) cracolândia(s) em São Paulo e no Rio de Janeiro. Anuário Antropológico, n. 2, p. 73-97, 2013 $<10.4000 /$ aa. $561>$.

GABORIAU, Patrick. Clochard: l'univers d'un groupe de sans-abri parisiens. Paris, Julliard, 1993.

GIROLA, Claudia. Rencontrer des personnes sans-abri: une anthropologie réflexive. Politix, n. 34, p. 87-98, $1996<10.3406 /$ polix.1996.1033>.

GIROLA, Claudia. De l'homme liminaire à la personne sociale: la lutte quotidienne des sans-abri. Paris: Ehess, 2007. Tesis de doctorado.

GOFFMAN, Erving. Asylums: essays of the social situation of mental patients and others inmates. New York: Anchor Books Doubleday, 1961.

LAPLANTINE, Francois. La description ethnographique. Paris: Nathan, 1998.

MARTÍNEZ MURILLO, Sandra. Miradas callejeras de ciudad. Experiencias juveniles entre El Cartucho y San Bernardo. Bogotá: Universidad Pedagógica Nacional, 2015. Tesis de maestría. 
MÚNERA RUÍZ, Leopoldo. Las relaciones de poder. In: Alejo Vargas Velásquez (ed.). Constitución, gobernabilidad y poder. Bogotá, Universidad Nacional de Colombia, 1996. p. 47-75.

NAEPELS, Michel. Ethnographie, pragmatique, histoire: un parcours de recherche à Houaïlou (Nouvelle-Calédonie). Paris: Publications de la Sorbonne, 2011.

OLIVIER DE SARDAN, Jean-Pierre. La politique du terrain: sur la production de données en anthropologie. Enquête, n. 1, p. 71-109, $1995<10.4000 /$ enquete.263>.

PICHON, Pascale. Vivre dans la rue: sociologie des sans domicile fixe. Saint-Étienne: Publications de l'Université de Saint-Étienne, 2010.

RITTERBUSCH, Amy. A youth vision of the city: the socio-spatial lives and exclusion of street girls in Bogotá, Colombia. Miami: Florida International University, 2011. Tesis de doctorado.

RODRÍGUEZ LIZARRALDE, Carolina. Cuerpos femeninos callejeros: hacia una política social con enfoque de género en Bogotá. Bogotá: Pontificia Universidad Javeriana, 2014. Tesis de maestría.

RUI, Taniele. Corpos abjetos: etnografia em cenários de uso e comércio de crack Campinas: Universidade Estadual de Campinas, 2012. Tesis de doctorado.

TEJEDA, José Luis. Biopolítica, población y control. Revista Memoria Académica, n. 12, p. $25-38,2010$.

Recibido: 30 mayo 2018

Acepto: 25 nov. 2018

Publicado: 01 marzo 2019

Autora correspondiente:

Carolina Rodríguez Lizarralde

Carrera 136 \# 17F-20

Bogotá, Colombia

NATALY CAMACHO MARIÑO < natcamachomarino@gmail.com>

Doutoranda em antropologia e sociologia, Laboratoire de changement social et politique, Université Paris Diderot 7 (Paris, França).

Orcid: https://orcid.org/0000-0003-1015-6474

CAROLINA RoDRÍGUEZ LIZARRALDE < crodriguez213@gmail.com>

Politóloga, Magistra en política social y Especialista en derechos humanos y derecho internacional humanitario, Universidad Nacional de Colombia (Bogotá, Colômbia).

Orcid: https://orcid.org/0000-0002-4700-9374 